\title{
Ventricular Tachycardia in a Patient with Repaired Tetralogy of Fallot
}

Anthony B Campbell, William F McIntyre and Adrian Baranchuk*

Cardiac Electrophysiology and Pacing, Kingston General Hospital, Queen's University, Kingston, Ontario, Canada

\begin{abstract}
We report a 22 year old male presenting to the emergency department with a symptomatic wide complex tachycardia. We discuss the algorithms to determine the origin of the tachycardia, and we analyzed in detail his 12lead ECG in sinus rhythm. Most frequent ECG patterns in repaired tetralogy of Fallot are also discussed.
\end{abstract}

Keywords: Ventricular tachycardia; Tetralogy of fallot; Ventricular arrhythmia; Congenital heart disease

\section{Case Presentation and ECG Description}

A 22 year old male presented to the emergency department with malaise, nausea and vomiting after consuming alcohol. A 12 lead ECG (Figure 1a) revealed a regular, wide complex tachycardia (QRS duration $144 \mathrm{~ms}$ ), ventricular rate $208 \mathrm{bpm}$, left bundle branch block morphology in lead V1 with inferior to superior axis. The third QRS complex in lead I (and the sixth complex in lead V5) is narrow and distinct from the rest of the QRS complexes.

The differential diagnosis of this tachycardia was ventricular tachycardia (VT) versus supraventricular tachycardia (SVT) with aberrancy. The Brugada algorithm [1] supports the diagnosis of VT in this case due to the presence of an RS interval $>100 \mathrm{~ms}$ in leads V1V2; however, there is no clear AV dissociation and the $\mathrm{R} / \mathrm{s}$ relation is 1 in lead V6. The diagnosis of VT is also supported by the Vereckei algorithm [2], due to the presence of the notch on the descending limb of a predominantly negative QRS and $\mathrm{q}>40 \mathrm{~ms}$. Analysis of the patient's ECG in sinus rhythm reveals that the narrow-complex QRS in leads I and V5 were capture beats, and is thus, highly suggestive of VT.

The patient was unstable and was DC cardioverted into stable sinus rhythm. His post-cardioversion 12 lead ECG shows (Figure 1b): Sinus rhythm, heart rate $85 \mathrm{bpm}$, left axis deviation (QRS axis $\left.-30^{\circ}\right)$, prolonged P-R interval (216 ms) and prolonged QT interval (QTc 564). The $\mathrm{P}$-wave duration is greater than $120 \mathrm{~ms}$ with a negative component in lead III indicating inter atrial block. Right bundle branch block (RBBB) with an RSR' in lead V1 pattern is also observed. Fragmentation of the QRS complex (fQRS), defined as $>2$ notches on the $\mathrm{R}$ wave or $\mathrm{S}$ wave [3], is present in all leads, but quite remarkable in the inferior and right precordial leads.

\section{Points to Ponder}

This patient had a history of tetralogy of Fallot corrected at three months of age. Following cardioversion, the patient was referred to a quaternary congenital centre for consideration of implantation of a cardioverter defibrillator.

This interesting ECG highlights the importance of recognizing the electrocardiographic findings of VT, as well as corrected tetralogy of Fallot. The ECG pattern of RSR' RBBB, left axis deviation, interatrial block and QRS fragmentation (fQRS) strongly suggests a diagnosis of tetralogy of Fallot. The Brugada and Vereckei algorithms are useful tools to assist in differentiating VT from SVT with aberrancy [1,2]. During surgical correction of tetralogy of Fallot, the ventricular septal defect is closed with a Dacron patch. Additionally, the right ventricular outflow tract obstruction is often relieved by resection of infundibular muscle and insertion of a right ventricular outflow tract or transannular patch. This often results in an ECG pattern of RSR' RBBB, left axis deviation and interatrial block. In patients with repaired tetralogy of Fallot, fQRS has been associated with right ventricular dysfunction, fibrosis and right ventricular outflow tract aneurysms $[3,4]$. Sustained VT is occasionally seen in patients with repaired tetralogy of Fallot, and is more common in those with structural abnormalities of the right ventricle [5]. In the presented case, echocardiographic investigation revealed severe pulmonary and tricuspid regurgitation. Ventricular tachycardia in the setting of corrected tetralogy of Fallot may result in deterioration of ventricular function, and even death. The presence of fQRS in a patient

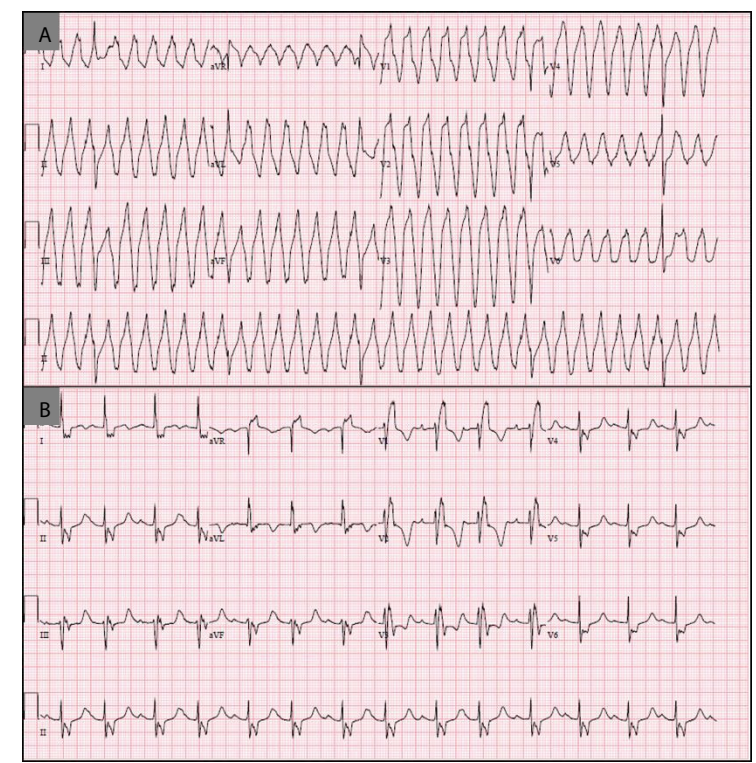

Figure 1: Panel A: 12-lead ECG depicting wide complex tachycardia. Panel $\mathrm{B}$ : 12-lead ECG during sinus rhythm. Note characteristic features of tetralogy of Fallot.

*Corresponding author: Dr. Adrian Baranchuk, MD FACC, Assistant Professor of Medicine and Physiology, Cardiac Electrophysiology and Pacing, Kingston General Hospital K7L 2V7, Queen's University, Kingston, Ontario, Canada, Tel: 6135496666, ext 3801; Fax: 613548 1387; Email: barancha@kgh.kari.net

Received July 09, 2013; Accepted August 14, 2013; Published August 20, 2013

Citation: Campbell AB, McIntyre WF, Baranchuk A (2013) Ventricular Tachycardia in a Patient with Repaired Tetralogy of Fallot. J Gen Pract 1: 120. doi: 10.4172/23299126.1000120

Copyright: (c) 2013 Campbell AB, et al. This is an open-access article distributed under the terms of the Creative Commons Attribution License, which permits unrestricted use, distribution, and reproduction in any medium, provided the original author and source are credited. 
Citation: Campbell AB, Mclntyre WF, Baranchuk A (2013) Ventricular Tachycardia in a Patient with Repaired Tetralogy of Fallot. J Gen Pract 1: 120. doi: 10.4172/2329-9126.1000120

Page 2 of 2

with corrected tetralogy of Fallot may be an indicator for increased risk of arrhythmias. Following an arrhythmic event, consideration of implantation of a cardioverter defibrillator is warranted. Alternate treatments include radiofrequency catheter ablation, tissue resection and medical therapy with amiodarone.

\section{Conclusion}

A characteristic pattern of corrected tetralogy of Fallot can be recognized on surface 12-lead ECG. The presence of fragmented QRS in the ECG of a patient with corrected tetralogy of Fallot may be an indicator of myocardial scar and risk for ventricular arrhythmia.

\section{References}

1. Brugada P, Brugada J, Mont L, Smeets J, Andries EW (1991) A new approach to the differential diagnosis of a regular tachycardia with a wide QRS complex. Circulation 83: 1649-1659.

2. Vereckei A, Duray G, Szénási G, Altemose GT, Miller JM (2008) New algorithm using only lead aVR for differential diagnosis of wide QRS complex tachycardia. Heart Rhythm 5: 89-98.

3. Shanmugam N, Yap J, Tan RS, Le TT, Gao F, et al. (2012) Fragmented QRS complexes predict right ventricular dysfunction and outflow tract aneurysms in patients with repaired tetralogy of Fallot. Int J Cardiol 67: 1366-1372.

4. Park SJ, On YK, Kim JS, Park SW, Yang JH, et al. (2012) J Relation of fragmented QRS complex to right ventricular fibrosis detected by late gadolinium enhancement cardiac magnetic resonance in adults with repaired tetralogy of fallot. Am J Cardiol 109: 110-115.

5. Harrison DA, Harris L, Siu SC, MacLoghlin CJ, Connelly MS, et al. (1997) Sustained ventricular tachycardia in adult patients late after repair of tetralogy of Fallot. J Am Coll Cardiol 30: 1368-1373. 